\title{
A Call for Investigation into Aesthetics and Beauty
}

\author{
Michael F Shaughnessy* and Jayson Evaniuck \\ Eastern New Mexico University, USA \\ *Corresponding author: Michael F Shaughnessy, Eastern New Mexico University, Portales, New Mexico, USA
}

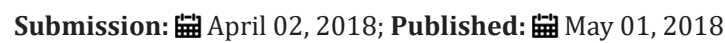

\begin{abstract}
The appreciation of art, music, dance, theatre, drama, and the humanities is not relegated to only the young. The elderly can have the same appreciation of pictures, a concert, a symphony, and a good book as anyone younger. This paper requests an examination into this realm and implores an investigation into how to provide the elderly with opportunities to enjoy beauty and aesthetics, and the importance of these elements to their quality of life. Needed research agendas will be explored.
\end{abstract}

In the realm of gerontology, there is a lack of theorizing about how the elderly or those who are aging appreciate, or learn to appreciate the arts and the humanities. This paper will review some of these concerns and reflect on the need for empirical investigation into this realm. All too often, the elderly are confronted with a number of perhaps health problems or ambulatory problems which restrict their ability to attend concerts, visit museums and explore other parts of the world in appreciation of culture, churches, panoramic views and vistas and the literature and poetry of other nations of the world. On the other hand many individuals remain able to attend literary events, savor paintings, and learn about the Impressionists and other forms of music such as baroque or symphonic music.

There needs to be a concerted effort to assist those who are still interested in learning about the arts and the humanities, and those who may want to reminisce and review prior learning's from other courses. Seniors and their spouses need to be encouraged to delve into new realms of deep appreciation of whatever realm of beauty they are most interested in. For some it may be the architecture of a certain time period, for others it may be a certain singer, for example Frank Sinatra or Duke Wellington, and still for others-they may want to glance back and again hear on You Tube the rock and roll of the 1960's and re-experience the Beatles.

Such endeavours should be understood and perhaps even empirically investigated. The arts and humanities contribute to the quality of life for many individuals and continue to enrich the lives of many people in many ways-auditorially, visually, spiritually and in other ways.

\section{Music as a Channel or Venue}

Music has been with us all for many years. In our childhood, we were exposed to Christmas Carols and other vocal and or choir performances and indeed may have participated as a tenor or bass or soprano and even participated in a church choir or local vocal group. In the realm of music therapy with the elderly, recalling certain songs brings back reflections of a time period, or a special someone or an event that holds deep, intimate memories. For some, it may be a special song that was played during one's wedding. For others, they recall the joy and pride when they graduated and heard that familiar Pomp and Circumstance by Elgar.

\section{The Visual Realm}

As long as a person is able to see, they are able to ponder a sunset, enjoy a tree, and the clouds. These things bring great joy to some individuals who may not be ambulatory and able to get to the Grand Canyon or to see the Eiffel Tower once more.
Many of us remember our first exposure to a painted picture or reproduction- such as the Last Supper, and then we recall seeing an actual sculpture or perhaps even a photograph or post card. Some individuals were fortunate enough to have actual art lessons as a child or adolescent, and perhaps those skills, while dormant for a while could be revived. The story of "Whistler's Mother" is often told about "late bloomers" who seem to be re-energized when they enter retirement or their golden years.

Today, with technology, and the Internet, one can enjoy a virtual trip to a museum. One can hear a lecture about art, or sculpture via educational software. And one can continue to appreciate the subtle nuances of art, balance, and perspective.

One such example of an option for the geriatric individual is the "Museum on Line". While some of these links may not be functional, there are many opportunities for the elderly to travel to 
a museum and take a "virtual tour". For example, here are a plethora of opportunities for those individuals who have never experienced the great city

\section{Museums of London \\ www.thebritishmuseum.ac.uk \\ www.rca.ac.uk \\ www.royalacademy.org.uk \\ www.serpentinegallery.org \\ www.courtauld.ac.uk \\ www.cam.ac.uk \\ www.nhm.ac.uk \\ www.photonet.org.ukwww/jojnjones.co.uk \\ www.tate.org.uk \\ www.guildhall-art-gallery.org.uk \\ www.whitechapel.org \\ wwww.londonprintstudio.org.uk \\ www.estorickcollection.com \\ www.delfina.org.uk \\ www.gasworksgallery.ortg \\ www.geffrye-museum.org.uk \\ www.transportoflondon.gov.org \\ www.tube.com \\ www.tflwap.gov.uk}

While not all of these museums or sites may appeal to all individuals, these do provide a rich robust opportunity to see some of these treasures of past years. A more global list of museums in the United States and around the world follows. Thus, individuals can travel to various sites around the world and investigate and explore beauty in depth.

\section{Museum of Online Museums}

http://www.coudal.com/moom.php

Smithsonian museums

http://www.si.edu/

Guggenheim

http://www.guggenheim.org/

American Association of Museums

http://www.aam-us.org/

Harvard Museums

http://www.artmuseums.harvard.edu/home_content.html
Vatican Museums

http://www.christusrex.org/www1/vaticano/0-Musei.html

Museums Online South Africa

http://media1.mweb.co.za/mosa/

Carnegie Museums

http://www.carnegiemuseums.org/carnegie/index.htm

Museum Spot

http://www.museumspot.com/

Natural History Museums

http://www.lib.washington.edu/sla/natmus.html

Association of Children's Museums

http://www.childrensmuseums.org/index.htm

Peabody Museum

http://www.peabody.harvard.edu/

Discovery Museums

http://www.discoverymuseums.org/

Unusual Museums on the Internet (scroll down past the google ads)

http://www.ringsurf.com/netring?ring=museum;action=list

\section{Musee}

http://www.musee-online.org/

Farm and Agriculture Museums

http://www.alhfam.org/alhfam.links.html

Art Source Museums

http://www.ilpi.com/artsource/museum.html

Sports Museums

http://www.sportshalls.com/

Top 100 Museums of the World

http://www.museum.com/jb/diatop100

Hollywood Museums

http://www.seeing-stars.com/Museums/

Japanese Museums

http://www.lib.duke.edu/ias/eac/museums.htm

Railroad Museums

http://www.railmuseums.com/

New Zealand Museums

http://www.nzmuseums.co.nz/ 
Aviation Museums

http://www.bb62museum.org/airmus.html

Medieval Museums

http://www.newyorkcarver.com/museum.htm

Museums of Greece

http://www.greece-museums.com/

UK Maritime Museums

http://www.cus.cam.ac.uk/ mhe1000/marmus.htm

Amsterdam Museums

http://www.biddingtons.com/content/bentleyamsterdam. html

Australian Museums

http://www.austmus.gov.au/

Masonic Museums in Europe

http://www.ammla.org/

Museum of Latin American Art

http://www.molaa.org/molaa_at_a_glance.html

US Museums by State

http://www.aam-us.org/museumresources/accred/list. cfm?mode=state

\section{Some Theoretical Background}

Numerous researchers Rebok [1] \& Willis [2] have demonstrated the benefits of cognitive training for improved cognitive reasoning and everyday functioning for elderly individuals. In view of cognitive training for the elderly, the power of emotion, imagery, and aesthetics needs further consideration. Research indicates emotionally stimulating information is better retained in the memory Cahill, Heur, Paivo [3-5]. Paivio [6] demonstrated that images provided a stronger memory trace than verbal code words. This is often referred to as the picture superiority effect.

Mcbride, Weldon, Roediger [7-9] demonstrated that pictures generate more explicit measures of memory function (recall and recognition) in experimental studies. The studies attest to the fact that memory works in myriad ways. The powers of aesthetics and emotion have been well documented by Gerald Cupchick [10]. Based on previous research, aesthetics oriented experiences hold significant potential for improving cognitive functions, memory and quality of life for the elderly.

\section{Art Experience and the Elderly}

The quality of life is measured by the repertory of feeling which pervades it. Life is rich if the repertory of feelings is large and the discrimination among them fine. Life is coarse, brutish, and violent when the repertory is meager and undifferentiated [11].
Arts related experiences and education are not limited to field trips and art classes experienced in younger ages. Rather, the authors argue elderly populations equally benefit from arts related experiences. Aesthetic experiences such as a museum visit, musical performance, or a theatre production promote emotional connections and reasoning. Emotional connections are crucial for elderly cognitive activity. Many elderly have vivid memories relating with personal and national historic events. Recollections of living through a war, the Great Depression, or even an interest in reading historic themes books are permanently etched within an individual's memory store. Exploration of the arts can tap in to such memories in the realms of history, literature, and the humanities while stimulating new learning.

Upon gazing at John Trumball's gripping portrait, The Battle of Bunker Hill, the individual makes a profound emotional connection instantly humanizing the epic battle. Or possibly the portrait conjures up fond memories of playing a soldier in the battle for a 5 th grade school play.

Maybe, the elderly women when exploring a Mississippi River museum exhibit instantly recalls feeling captured by reading the works of Mark Twain. The memory combined with an emotional aesthetic connection then promotes deeper reasoning beyond a simple nostalgic reminiscence. Such emotional and cognitive associations are paramount for enhancing elderly brain functions of memory and reasoning.

Further, the experiences in the aesthetic realm enhance the quality and richness of life. Attending an art museum with a nursery home tour bus is indeed an enlightening experience for elderly but should be enriched when possible to promote the aforementioned cognitive functions. Noted aesthetics educator Broudy [11] advocated for a disciplined approach towards existentially connecting with aesthetic material and learning from it.

Visual and performing arts involve critical details of form, technique, artist's perspective, and the historical context from which they developed. Such characteristics may not always be comprehensible with a cursory experience. The power of a museum docent holds great potential in unlocking such minutia for elderly museum visitors Wilburn [12]. Recent technological advances make a structured and educational experience more accessible for visually and hearing impaired museum goers. Most major museums are now utilizing audio assisted technology to guide visitors through exhibits at their own pace.

Feldman [13] demonstrated the benefits of theatre as entertainment as well as educational for elderly individuals. Often theatre companies have community and educational outreach programs extending beyond school-aged children. For instance, if a nursing home is planning on attending a production such as Macbeth, Les Miserable's, Showboat, Hamilton, or Sophocles, an educational visit could inform viewers on overarching themes and historical context of the work prior to viewing. Such knowledge deepens the aesthetic experience beyond entertainment value 
facilitating an emotional and rational connection thereby encouraging cognitive activity.

Often, there are educational C.D.'s that can transport one to a museum, and a guide or professor is available to provide some background and information about a certain painting or sculpture. Some of these links provide guidance from curators and provide viewing from various angles about a certain sculpture or painting. One organization that has a number of Museum C.D.'s is The Great Courses. These educational CD are narrated by the very finest professors in their fields and contain excellent commentary as to the background of various visual artifacts.

Once a person gets onto a list serve, the specific museum of interest will send them periodic updates.

One such update involved a discussion about a specific painting of interest.

https: / / www.facebook.com/thenationalgallery/ vi d e o s / 10101600034800000905557 ? u t m c a m paign = 598884_2018 M a r ch_Green \& ut m source $=$ dotmailer $\&$ utm_medium $=$ e mail $\& u t m$. content=facebooklive_button In the above link, the viewer is transported to the National Gallery, where an expert is introduced, the Painting is seen, and details discussed.

Theodore Dalrymple [14] has posted a most intriguing article online regarding the "elderly" and their continued interest in museums, and in learning. The entire article can be accessed herehttps://www.city-journal.org/html/o-brave-old-world-15612. html but his points are all salient and relevant and germane. Dalrymple in his usual observations of the world encountered some elderly (and the authors put the words in quotes above so as to not offend anyone) ladies enjoying a presentation at the British Museum and struck up a conversation with them, and found to his somewhat dismay, that they were still involved in learning. They essentially began learning when young and the love of learning continued well into their 80 's and 90's. No doubt these "little old ladies" made frequent stops to the National Gallery and a number of other museums in the wonderful city of London, perhaps even visiting Dickens' "Little Old Curiosity Shop". His point essentially was that people can continue to espouse interest, express interest in learning about artifacts, archaeology and anthropology- even though they may never practice the trade or craft of any of these. "Isn't that interesting" is a phrase not often heard- but hopefully many of our fellow individuals will continue to find things of interest and pleasure that enchant us and pique our interest.

Often, a more simple approach would be preferable for some. There are many excellent art appreciation books which would yield a wealth of information and pleasure and enjoyment. Forty [15] has one such book specifically devoted to Michelangelo. The paintings of Vincent Van Gogh have received much attention, and while most individuals are familiar with "Starry Starry Night", Van Gogh has left behind a treasure of work which remains unseen or hidden in various museums around the world. Various impressionist artists, such as Monet and Manet can be explored, compared and contrasted.

For those in a residential setting or skilled health care providing facility, the staff should be aware that those individuals still see colors and appreciate art, beauty and drawings, sketches and paintings. Indeed, pictures by Normal Rockwell may do much to bring back early childhood memories and thoughts of loved ones. The Last Supper is another painting that seems to have permeated the homes of millions of individuals and remains an important part of every home, and their spiritual lives.

\section{Architecture-The Appreciation of Perspective}

The works of man bear particular examination. Over the centuries, man has constructed cathedrals, churches, monuments, statues and a number of other buildings, some of which remain today (for example the Eiffel Tower, and the Arc De Triumphe) Man has constructed flying buttresses, pyramids, The Great Wall of China and other monuments to man's creativity and desire to praise the Lord. The world is replete with various types of architecture such as the Taj Mahal and the various wonders of the World. Pictures of London Bridge, Buckingham Palace, and other well known scenes can also provide some perspective on architecture, and the architecture of the past.

In terms of architecture and perspective, if the individual has access to the Internet, they are able to use Google Earth to travel to just about any city or town on the globe. Thus, they will be able to see the Cathedral of Notre Dame from various perspectives- abovewith a bird's eye view or even a worm's eye view. Google Earth can take individuals to all of the streets and boulevards of Paris, and allow individuals to explore the arrondisements of Paris- such as Montmartre, to see the SacreCour and Versailles on the outskirts of Paris.

\section{Religion and the Appreciation of Ritual}

Religion offers comfort and solace to many, and for those in the twilight years of their lives, their appreciation of the Bible, the liturgy, the Rosary and various other spiritual domains is an anchor for their lives, and a final area of appreciation. Indeed, the local church or synagogue may contain much to be appreciative of. The stained glass windows, the chalice, the bodice and the various rituals that are engaged in, are in fact, beautiful to many, and offer a spiritual lift as well as comfort for their trials and tribulations. The time period before Christmas, the 40 days before Easter and the various celebrations that some religions espouse need to be appreciation and indeed, be seen as part of a glorious work of art, if you will. Many churches offer Mass, prayer events, and celebrations for baptism, confirmation, and other events. Many individuals have attended services for years, but have never stopped to truly appreciate the warmth and comfort of the Old Testament, the New Testament or specific books such as Psalms and Proverbs.

\section{The Auditory Realm of Music}

While many of us have heard the names of Bach, Beethoven, Brahms, and many others, there are many other artists that can 
still be explored and appreciated. Berlioz, Vivaldi, Schubert, and many other composers can be listened to on the radio, some public Broadcasting stations, and via cassettes and dare I use the word, records. Further colleges and university music departments offer free concerts, recitals and provide a number of experiences that provide an exposure to students regarding various types of musicjazz, baroque, calypso, and the like.

For some individuals, listening to Christmas carols and country and western songs can be just as appealing, but exposure to Hawaiian music can also help with some degree of anxiety and facilitate some relaxation. For some individuals, the local library has a collection of cassettes as well as records and on occasion, a librarian will suggest some options and alternatives. In some "Elderhostel" programs, there are special mini courses to expose individuals to a new form of music or to reintroduce an artist, writer or composer with which a person may not be familiar. Subtle nuances can be discerned and different melodies appreciated.

Each country of the world has their own singular type of music, and African tribal music can be appreciated as much as Korean music. One may never have been exposed to Gregorian chants, and one's retirement years offer a special time to investigate these things. The arts and the humanities should continue to provide a rich understanding of the world around us as well as art, beauty and aesthetics.

\section{The Need for Research}

There has been scant empirical research on the infusion of the arts into the lives of the elderly. Little has been written about the emotional life as enhanced by a purposive study of literature (have you read everything Charles Dickens has written?) music (is it too late to study flute?) or art (can you use water colours or shape with clay or some other material?) Certainly, some individuals have physical or medical restraints that restrict their ability to travel to the Pantheon to study architecture first hand. Not everyone can climb Mt. Pilatus to gain a panoramic view of the Swiss Alps. And not everyone has the motivation to enjoy the grandeur and splendour of all of the works of the Renaissance and Da Vinci. There are those readers who may want to delve more deeply into the various realms of the humanities and a book by Shaughnessy $[16,17]$ provides chapters by leading individuals in the realms of music, American history, the intersection and interaction of the humanities and aesthetics and emotion, scripture, multiculturalism, American historical theatre, and interestingly enough, there is a new realm of the humanities referred to as "space history" which chronicles man's race into space and the trials and tribulations of those endeavours.

\section{Summary and Conclusion}

This paper has simply provided a small foundation of a small realm of study- the idea of using and infusing the arts and humanities into the lives of those in the "twilight of their years". Several realms have been addressed although there are many more to be explored. One wants to live as rich and robust a life as possible and the humanities provide such an avenue for a full complete life. In the words of Dalrymple [14] "No doubt a happy old age is largely a matter of luck, but it must also be partly a matter of attitude to the world, so various, so beautiful, so new".

\section{References}

1. Rebok GW, Ball K, Guey LT, Jones RN, Kim HY, et al. (2014) Ten-year effects of the advanced cognitive training for independent and vital elderly cognitive training trial on cognition and everyday functioning in older adults. J Am Geriatr Soc 62(1): 16-24.

2. Willis S L, Tennstedt SL, Marsiske M, Ball K, Elias J, et al. (2006) Longterm effects of cognitive training on everyday functional outcomes in older adults. Jama 296(23): 2805-2814.

3. Cahill L, McGaugh JL (1995) A novel demonstration of enhanced memory associated with emotional arousal. Consciousness and cognition 4 (4): 410-421.

4. Heuer F, Reisberg D (1990) vivid memories of emotional events: The accuracy of remembered minutiae. Mem cognit 18(5): 496-506.

5. Paivio A, Csapo K (1973) Picture superiority in free recall: Imagery or dual coding? Cognitive Psychology 5(2): 176-206.

6. Paivio A (1971) Imagery and language. In: Sydney JS (Ed.), Imagery: Current cognitive approaches. Academic Press New York, USA, pp. 7-32.

7. McBride DM, Dosher BA (2002) A comparison of conscious and automatic memory processes for picture and word stimuli: A process dissociation analysis. Consciousness and cognition 11(3): 423-460.

8. Weldon MS, Roediger HL (1987) Altering retrieval demands reverses the picture superiority effect. Mem Cognit 15(4): 269-280.

9. Roediger HL (1990) Implicit memory: Retention without remembering. American psychologist 45(9): 1043-1056.

10. Gerald Cupchik C (2016) The aesthetics of emotion: Up the down staircase of the mind body. Cambridge University Press, Cambridge, England.

11. Broudy HS (1972) Enlightened Cherishing. An Essay on Aesthetic Education, Urbana, University of Illinois Press, USA.

12. Wilburn D (2013) A Docent's Perspective: From Tour Guide to Advisor. Disability Studies Quarterly 33(3): 30.

13. Feldman S, Radermacher H, Lorains F, Haines T (2011) A research-based community theater performance to promote ageing: Is it more than just a show?. Educational Gerontology 37(10): 885-898.

14. Theodore Dalrymple (2017) https://www.city-journal.org/html/obrave-old-world-15612.html.

15. Forty S (2014) Michelangelo Charlotte, TAJ Books, North Carolina, US.

16. Shaughnessy MF (2015) The Humanities in 2015: Why we need them and how they contribute to our being human. Hauppauge, Nova Publisher, NewYork, USA.

17. Shaughnessy MF (2017) The Humanities: Past Present and Future Hauppauge, Nova Publishing, New York, USA 
Creative Commons Attribution 4.0 International License

For possible submissions Click Here Submit Article

GGS $\mid \underset{\substack{\text { Gerontology } \\ \text { Geriatics }}}{\operatorname{sindes}}$
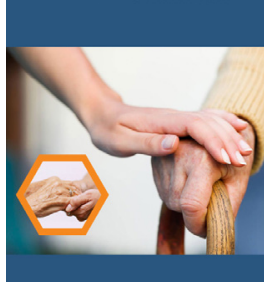

- Freely accessible online immediately upon publication

- Authors retain the copyright to their work

- Licensing it under a Creative Commons license

- Visibility through different online platforms 